\title{
Climate risk management for water in semi-arid regions
}

\author{
Andrew W Robertson ${ }^{1}$, Walter Baethgen ${ }^{1}$, Paul Block², Upmanu Lall ${ }^{3}$, Arumugam Sankarasubramanian ${ }^{4}$, \\ Francisco de Assis de Souza Filho ${ }^{5}$ and Koen M J Verbist 6,7
}

\begin{abstract}
Background: New sources of hydroclimate information based on forecast models and observational data have the potential to greatly improve the management of water resources in semi-arid regions prone to drought. Better management of climate-related risks and opportunities requires both new methods to develop forecasts of drought indicators and river flow, as well as better strategies to incorporate these forecasts into drought, river or reservoir management systems. In each case the existing institutional and policy context is key, making a collaborative approach involving stakeholders essential.
\end{abstract}

Methods: This paper describes work done at the IRI over the past decade to develop statistical hydrologic forecast and water allocation models for the semi arid regions of NE Brazil (the "Nordeste") and central northern Chile based on seasonal climate forecasts.

Results: In both locations, downscaled precipitation forecasts based on lagged SST predictors or GCM precipitation forecasts exhibit quite high skill. Spring-summer melt flow in Chile is shown to be highly predictable based on estimates of previous winter precipitation, and moderately predictable up to 6 months in advance using climate forecasts. Retrospective streamflow forecasts here are quite effective in predicting reductions in water rights during dry years. For the multi-use Oros reservoir in NE Brazil, streamflow forecasts have the most potential to optimize water allocations during multi-year low-flow periods, while the potential is higher for smaller reservoirs, relative to demand.

Conclusions: This work demonstrates the potential value of seasonal climate forecasting as an integral part of drought early warning and for water allocation decision support systems in semi-arid regions. As human demands for water rise over time this potential is certain to rise in the future.

\section{Background}

Water scarcity in semi-arid regions having only one rainy season per year is a serious problem especially in developing countries. Seasonal climate forecasts, where they are skillful, provide a potential mechanism to manage drought in rainfed areas, and to better manage water allocation and reservoir operations. This paper describes approaches developed at the IRI in two semi-arid regions of South America, Central Chile, and NE Brazil covering these three aspects.

\footnotetext{
*Correspondence: awr@iri.columbia.edu

${ }^{1}$ International Research Institute for Climate and Society, The Earth Institute, Columbia University, Palisades, New York, USA

Full list of author information is available at the end of the article
}

\section{The central Chile case study}

Climate variability can have serious social impacts in semiarid regions, especially for farmers who depend on rain-fed agriculture and on livestock production based on natural vegetation. In the Elqui Valley and Coquimbo region in central northern Chile (approx. 28S-32S), where rainfall amounts often drop under the limit for crop growth, a lack of rainfall results in a crisis situation for society. Over USD2.6 million were spent during the severe drought of 2007 to support affected families and farmers as they repair damage, recover degraded soils, and increase irrigation programs (MINAGRI 2008).

A typical problem here is the lack of preparedness prior to these natural events, making any governmental action afterward less cost effective. Despite the need, the current Drought Alleviation Plan formulated by the Chilean government for the region (FOSIS 2008) does not include

\section{是 Springer}

(c) 2014 Robertson et al.; licensee Springer. This is an Open Access article distributed under the terms of the Creative Commons Attribution License (http://creativecommons.org/licenses/by/2.0), which permits unrestricted use, distribution, and reproduction in any medium, provided the original work is properly credited. 
strategies for drought early warning, and the feasibility of such a system has yet to be demonstrated.

The majority of precipitation in the region falls during the austral winter (May-August) as rain in the Valley and snow in the mountains, leaving the remaining months extremely dry (Aceituno 1988; Carrasco et al. 2008). Total precipitation averages approximately $100 \mathrm{~mm}$ annually near the coast, with larger amounts towards the Cordillera and south, and with a high degree of interannual variability (Young et al. 2010). El Niño-Southern Oscillation (ENSO) has been identified as a strong driver of this variability, with positive precipitation anomalies during El Niño events and below normal precipitation mostly associated with La Niña conditions (Aceituno 1988; Montecinos and Aceituno 2003; Falvey and Garreaud 2007; Garreaud et al. 2009; Quintana and Aceituno 2012). The Elqui River is predominantly fed through snowmelt over the October-January season, and a skillful streamflow forecast could provide advanced information to guide water allocation decisions in the Valley, especially during drought.

During the 1980s and 1990s, the framework for privatized water in Chile was established to encourage optimal allocation and efficiency through a market-oriented approach, as prescribed by the Water Code of 1981 (Donoso 2006; Young et al. 2010). The national water authority initially issued water rights, while supervision is the responsibility of the local water authority. Rights along the Elqui River are fully allocated, with each right valued at 1 liter per second. In years with near normal or above normal precipitation and snowpack in the Andes, supply is typically sufficient for all holders to use the full 1 liter per second; however in years with less than normal precipitation and snowpack, a reduction in the water rights value is required, occasionally to 0.5 liters per second or even less. All water rights holders have equal priority. Farmers dominate the landscape, holding approximately $92 \%$ of all rights, with half of those held by a small minority practicing large-scale viticulture. Municipalities and the mining industry share the remaining rights. Skillful forecasts of potential water rights reductions may thus be informative for planning purposes across a number of sectors.

\section{The Nordeste case study}

Northeast Brazil is a region with a high potential for seasonal rainfall predictability during the February-April rainy season, due to strong teleconnections with ENSO and with variability of the tropical Atlantic Ocean (Hastenrath and Heller 1977; Moura and Shukla 1981; Nobre and Shukla 1996). Reservoir optimization results are shown for the Oros system, which is the upper most reservoir in the Jaguaribe-Metropolitan multi-reservoir system. Currently, a conservative policy is used in water allocation for municipal, industrial, and agricultural use, assuming zero inflow into the reservoir in the upcoming year-essentially assuming a drought will occur every year. The work reviewed here investigates the potential for climate forecasts to improve the water allocation and reservoir releases through pre-emptive optimization analyses that are used to guide subsequent land use and other water sensitive decisions in a collaborative setting.

\section{Methods}

\section{Seasonal climate forecasts}

The IRI has issued seasonal climate forecasts for precipitation and near-surface temperature over global land areas operationally since 1998. These "Net Assessments" are described in detail in a separate paper (Barnston et al., this volume). Issued in the form of shifts in the odds of below-normal, near-normal and above-normal tercile categories for three-month average conditions at lead time up to about 6 months, these forecasts can provide decision makers with a heads-up to anomalous conditions. The Net Assessment was designed for that purpose, consisting of a map that is blank where climatological probabilities are expected, and which is shaded in progressively stronger colors when and where the calibrated forecasts indicate large probability shifts toward a particular category. However, the global nature of the map, its use of tercile categories, and its focus on seasonal average conditions are not directly useful for quantitative decision making in any particular instance. For drought management over rainfed areas, as well as the best use of limited water resources from rivers, research has been done at IRI and elsewhere to tailor seasonal climate forecasts for particular water decision making contexts.

Northeast Brazil exhibits some of the highest rainfall skills on the globe in the IRI Net Assessment, while the skill is comparatively low over Chile (Barnston et al. 2009). We summarize several methodologies used to enhance, downscale and tailor seasonal climate forecasts for drought management and streamflow forecasting for the Chile and NE Brazil case studies below.

\section{Downscaling of daily rainfall characteristics for drought management over Chile}

The character of daily rainfall within a season, often termed "weather within climate" is known to be more relevant for agriculture and water resource management than seasonal rainfall total and thus for agricultural drought. Dry spells (low rainfall frequency) can cause drought stress especially during the flowering stage of the crop (Challinor et al. 2004; Hansen et al. 2006). High-intensity downpours may run off without recharging soil moisture and may damage crops. By expressing seasonal total rainfall as the product of the number of rainy days (e.g. $>$ $1 \mathrm{~mm} /$ day) and the mean rainfall intensity on wet days, it 
has been shown that rainfall frequency is generally much more seasonally predictable in the tropics than mean intensity (Moron et al. 2006; Robertson et al. 2009). This has been attributed to the higher spatial coherence of seasonal anomalies of rainfall frequency at the station scale (Moron et al. 2006; Moron et al. 2007). Thus, seasonal forecasts of relevant daily rainfall statistics have the potential to be more skillful than forecasts of trimester rainfall amount.

One of the simplest yet effective methods to downscale general circulation model (GCM) seasonal forecasts to rainfall at the station scale is using regression approaches based on cross-validated principal component regression (PCR) or canonical correlation analysis (CCA) (Tippett et al. 2003), as implemented in IRI's Climate Predictability Tool (CPT) software (http://iri.columbia. edu/climate/tools/cpt); these procedures avoid the problems associated with multicollinearity in multiple linear regression. This approach was used to downscale (or tailor) precipitation hindcasts (forecasts made retrospectively for past years) of the NCEP Climate Forecast System version 1 (CFSv1) coupled ocean-atmosphere GCM (Saha et al. 2006) over Chile. The hindcasts were initialized on April 1 and expressed in terms of station-averaged standardized precipitation index based on station data for the May-August season for the years 1981-2005 (Verbist et al. 2010). This methodology has been shown to match or even to outperform more complex dynamical downscaling models over the Philippines (Robertson et al. 2011). The CPT formulation uses a regression model (either PCR or CCA) to calculate the mean of the forecast distribution, and the standard deviation of cross-validated error residuals of these values to determine the forecast spread, calculated from a Student's t distribution.

The CFSv1 15-member ensemble mean gridded precipitation was used over the domain $20 \mathrm{~S}-40 \mathrm{~S}$ and $65 \mathrm{~W}-85 \mathrm{~W}$.

Methods for spatio-temporal downscaling to obtain daily sequences of rainfall at the station level are of two general types: analog-type resampling approaches based on historical daily data such as weather-typing or Knearest neighbors approaches (Rajagopalan and Lall 1999; Gangopadhyay et al. 2005; Moron et al. 2008), or weather generator approaches such as the nonhomogeneous hidden Markov model (NHMM) (Hughes and Guttorp 1994; Charles et al. 1999; Robertson et al. 2006). In both cases, the stochastic models for daily rainfall sequences need to be conditioned on a predictor variable, which is either taken to be a measure of relevant antecedent climate conditions, such as the Niño 3.4 sea surface temperature (SST) index, or forecasts of precipitation over the region of interest. The performance of these methods was shown to be comparable over Senegal (Moron et al. 2008). Once the daily rainfall sequences have been calculated, the rainfall or drought statistic of choice can be easily calculated.
This is illustrated for Chile below, using the NHMM to forecast the number of heavy rainfall days (Verbist et al. 2010). The NHMM has also been applied over NE Brazil to downscale daily rainfall occurrence sequences to the station scale (Robertson et al. 2004).

\section{Hydrological models}

Seasonal streamflow forecasts based on climate information can guide water managers toward improved reservoir operations, leading to better water resources management efficiency. Uncertainty is always present in seasonal streamflow forecasts, affecting the forecast value. Kwon et al. (2002) (Kwon et al. 2012) found that uncertainties associated with the climate forecast are much larger than those from parameter estimation in the hydrologic model.

Streamflow forecasting approaches primarily fall into two categories: statistical or dynamical (climatichydrologic model integration). Statistical approaches directly estimate streamflow using predictors of SST or a related hydroclimatic index (e.g. (Souza Filho et al. 2003)). Dynamical approaches couple climate and hydrology processes by passing downscaled information in an iterative or static manner (e.g. (Wood et al. 2002)).

\section{Linear regression models - Chile}

Both purely statistical and dynamical-statistical streamflow prediction models have been developed to characterize October-January average streamflow at the Algorrobal station on the Elqui River, upstream of the Puclaro reservoir in Chile. The Algorrobal station acts as a proxy for inflow to the Puclaro reservoir, with daily records available from 1949-present. Presently, the dynamical-statistical approach is used for the May-issued forecast, while the purely statistical approach is used for the Septemberissued forecast; future work improving both techniques for both leads is warranted. The statistical model takes a PCR approach, evaluating numerous large-scale and local hydro-climatic predictors and observations in the preceding season. The dynamical-statistical approach uses the CFSv1 precipitation hindcasts and builds on the work of (Verbist et al. 2010) by relating predicted austral winter precipitation to summertime streamflow using PCR.

\section{Semiparametric models - NE Brazil}

Souza and Lall (2003) (Souza Filho et al. 2003) developed a semi-parametric approach for forecasting streamflow at multiple gauging locations on a river network in NE Brazil conditional on climate precursors. The strategy considers statistical forecasts of annual or seasonal streamflow totals at each of the sites and their disaggregation to monthly or higher resolution flows using a K-nearest neighbor (K-NN) resampling approach that 
maintains space-time consistency across the sites and subperiods. This approach is used to develop seasonal streamflow forecasts for the Oros system. A total of 1000 traces of retrospective monthly streamflow forecasts are constructed for the water-allocation year July-June, based on the previous April-June average Niño 3.4 and East Atlantic Dipole (EAD) [(5N-20N, 60W-30W) minus (020S, 30W-10E)] SSTs(Souza Filho et al. 2003). The basic premise is that future streamflows are weighted ensembles of past K similar conditions based on the current SST predictor conditions. For additional details, see (Souza Filho et al. 2003).

\section{Water rights forecasting in Chile}

Previously, the local water authority used an analog streamflow forecast conditioned on the multivariate ENSO index (MEI, (Wolter and Timlin 1998)) to prescribe reservoir operations, with mixed success (M. Dominguez, personal communication.). Although the predictive skill was only moderate, it is encouraging that the local water authority has been using forecasts explicitly as part of their decision strategy. Additionally, the water authority indicated they were free (institutionally) to use forecasts produced by others (e.g. NOAA providing the multivariate ENSO index), including local institutions, as long as the forecasts were not produced in-house for potential conflict of interest reasons. This motivated enhancement of the existing streamflow forecast framework to provide water rights value forecasts.

In the work described here, the value of water rights each year is conditioned on both the predicted October-January streamflow total and the existing volume of the Puclaro reservoir; however unless the Puclaro volume is uncharacteristically low, it is really the austral summer streamflow prediction that dictates. ${ }^{1}$ Water rights values are set in October of each year. For planning and management purposes, the local water authority issues statements of the predicted water rights value in advance of October. The first statement is issued in early May, providing a five-month lead; the second statement is issued in September, and represents the updated and finalized value. Forecasts of the water rights values are subsequently derived from the streamflow forecast and existing reservoir volume through a simple water balance.

\section{Forecast-based water allocation in NE Brazil}

A participatory water allocation process based on probabilistic forecasts was introduced by Sankarasubramanian et al., (2009) (Sankarasubramanian et al. 2009a).

Users request the quantity of water they need at a particular reliability, the temporal distribution of this "allocation" within the upcoming season or year, their willingness to pay, and compensation in the event of nondelivery. The water manager then assesses feasible allocations using the forecast that tries to meet these criteria across all users.

Figure 1 shows the allocation timeline in the basin with the participatory meeting held each July. Annual allocations are currently agreed upon for the three uses by assuming (a) zero inflows over the coming year, and (b) ensuring enough storage remains the following June to supply municipal water needs for an additional six months. Inflows into the Oros reservoir are largely confined to January-June, with irrigation needs mainly during August-November, while municipal and industrial demands are fairly constant throughout the year. Two recent studies (Sankarasubramanian et al. 2009a; Broad et al. 2007) provide a detailed discussion of the participatory water allocation process in Ceará and their relevance to seasonal streamflow forecasts.

The proposed framework consists of (a) a structure for water contracts, and (b) a water allocation model based on reservoir levels and streamflow forecasts (Sankarasubramanian et al. 2009a). The water allocation model is a (single site) multi-purpose reservoir optimization model that maximizes a utility function subject to the desired yield reliabilities, sectoral water allocation constraints and preferences (Lall and Miller 1988; Lall 1995). The yield denotes the reservoir releases for a future period with a given probability, which is usually expressed as its reliability of supply. In the traditional yield model, firm and secondary reservoir yields (corresponding to high and low reliability respectively)

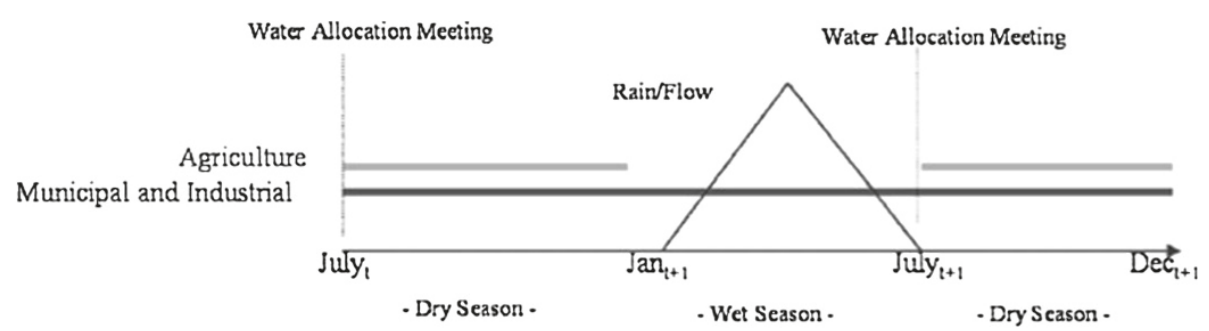

Figure 1 Water allocation decision timeline for the Oros reservoir, NE Brazil. Reproduced from (Broad et al. 2007). 
are calculated through simulation or stochastic analysis of historical streamflow data so as to maximize the long term performance of the reservoir over the planning horizon.

The key element of the framework is that if all the stakeholders agree on the end-of-season target storage and specify their desired reliability of supply, then the allocation model will determine the month-by-month reservoir releases required for each use, conditional on the probabilistic streamflow forecasts.

\section{Results and discussion}

\section{Downscaling of precipitation forecasts over Chile for} dryland management

Verbist et al. (2010) (Verbist et al. 2010) investigated the seasonal predictability of total seasonal rainfall total, daily rainfall frequency, and mean daily rainfall intensity on wet days at the station scale over the the Coquimbo region (the 4th administrative region of Chile), using station rainfall data obtained from Chilean Water Authority (DGA). CCA was used to downscale these seasonal rainfall summary statistics directly, while a large ensemble of daily rainfall sequences was simulated at each station using the NHMM, from which the rainfall summary statistics were calculated a posteriori. Similar cross-validated skill estimates were obtained using both approaches, with the highest anomaly correlations with observations found for seasonal rainfall amount and rainfall frequency (up to 0.9 at individual stations) (Verbist et al. 2010).

\section{Seasonal precipitation}

Figure 2 shows an extension of the work of (Verbist et al. 2010) to the 5th to 8th regions of Chile, which lie to the south of the 4th region; it shows the anomaly correlation coefficient (ACC) for cross-validated hindcasts of May-August (MJJA) station rainfall seasonal totals, 1981-2005, based on CFSv1 precipitation hindcasts initialized on April 1 and downscaled with the CPT. The hindcasts exhibit substantial skill at the station scale, ranging form about 0.6 in the north to about 0.4 in the south. This technique enables precipitation forecasts with appreciably higher skill than is obtained from the IRI Net Assessments (http://iri.columbia.edu/climate/ forecast/verification).

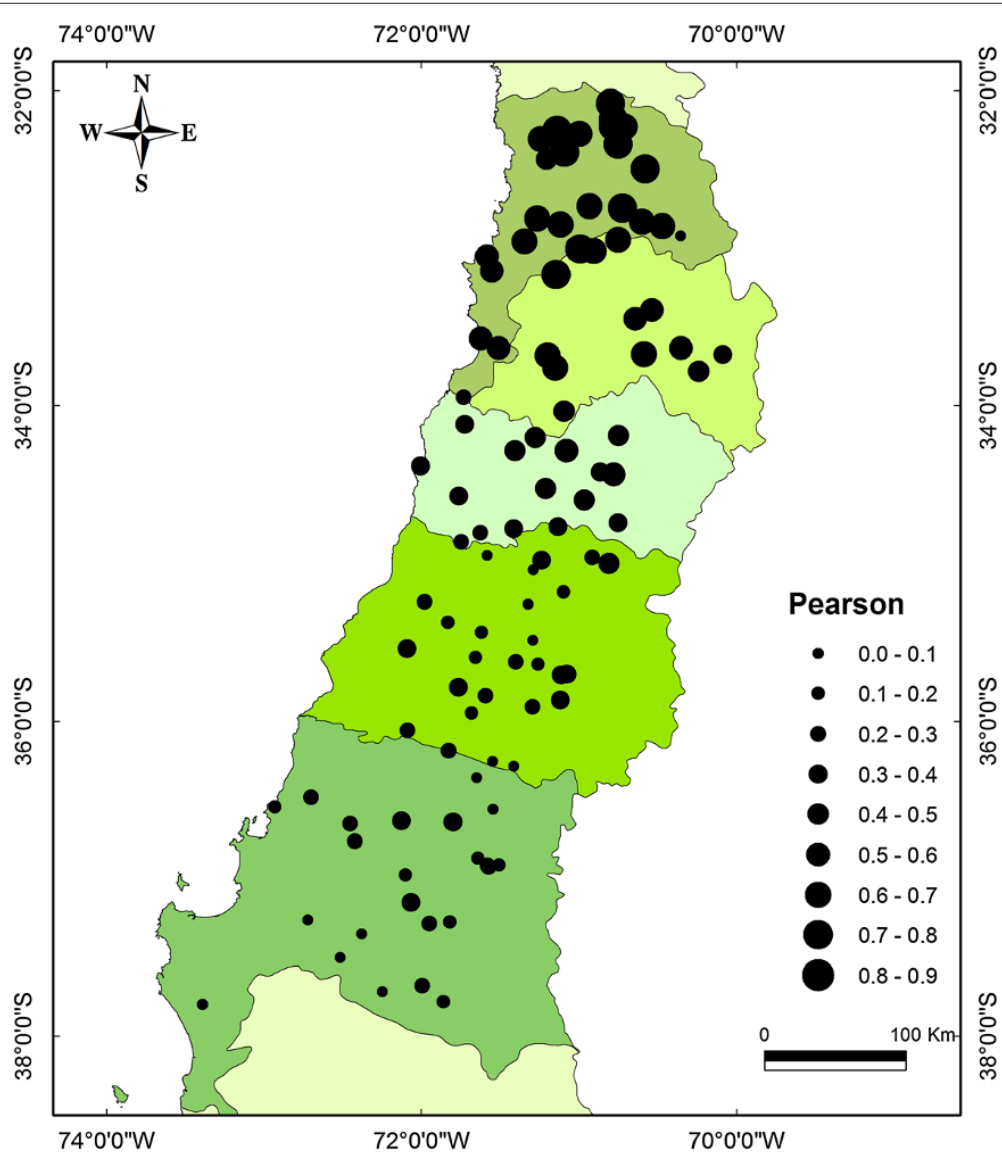

Figure 2 Anomaly correlation skill of May-August station precipitation for the 5th-8th regions of Chile, downscaled from CFSv1 hindcasts issued on April 1 (1981-2005). 
Figure 3 shows the mean of the hindcasts in terms of the standardized precipitation index (SPI), a commonly used meteorological drought classification method (Guttman 1998), averaged over the stations in the 5 th and 6th regions respectively; considerable agreement with observations is apparent, particularly in the former.

\section{Daily rainfall sequences}

Given the potentially useful drought prediction skill through the use of downscaled seasonal climate forecasts seen in Figures 2 and 3, the work of (Verbist et al. 2010) further investigated whether drought-relevant daily characteristics of rainfall could also be predicted. Figure 4 shows the estimated sequence of daily rainfall states in the 4th region, calculated from the daily rainfall station data with an HMM. The four HMM rainfall states are ranked from driest (state 1) to wettest (state 4). Clearly even the winter rainy season is dominated by the dry state, with rainfall only occurring in short sporadic episodes of the wet states. Figure 5 illustrates the patterns of atmospheric pressure anomalies at mean sea level (MSLP), which indicate that the wet states are characterized by a surface trough striking the coast, and a synoptic wavetrain extending upstream over the South Pacific. The intensity of the rainfall of each HMM state correlates with the intensity of this synoptic wavetrain, rather than with different types of pressure pattern. The HMM state decomposition thus provides potentially valuable physical insight into the mechanisms of rainfall and drought over a region. Similar circulation regimes over the South Pacific sector have been linked to extratropical intraseasonal oscillations (Robertson and Mechoso 2003), while recent evidence suggests that winter precipitation in Chile
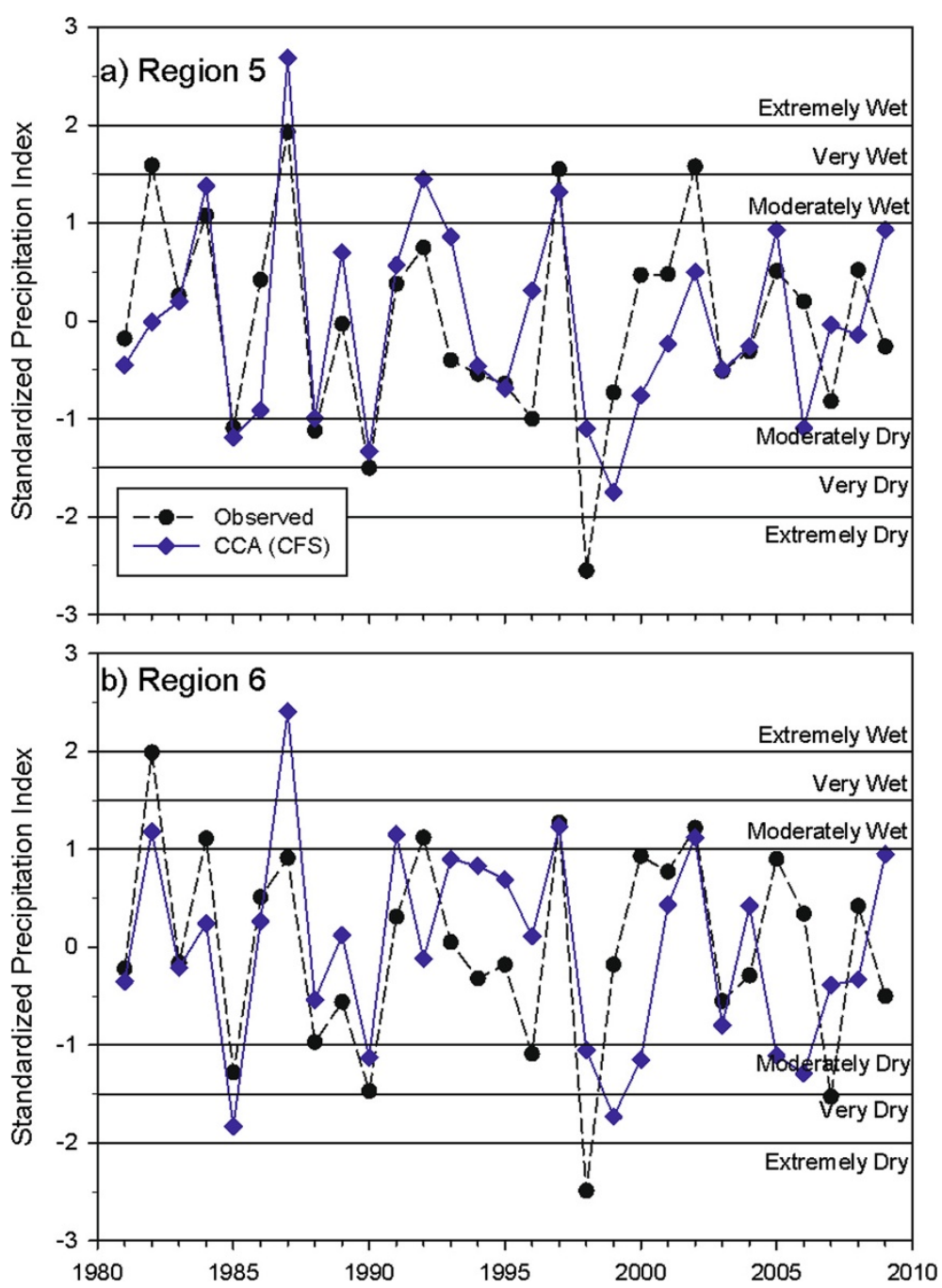

Figure 3 Station-averaged hindcasts of the May-August SPI for the (a) 5th region, and (b) 6th region of Chile. As Figure 2. 


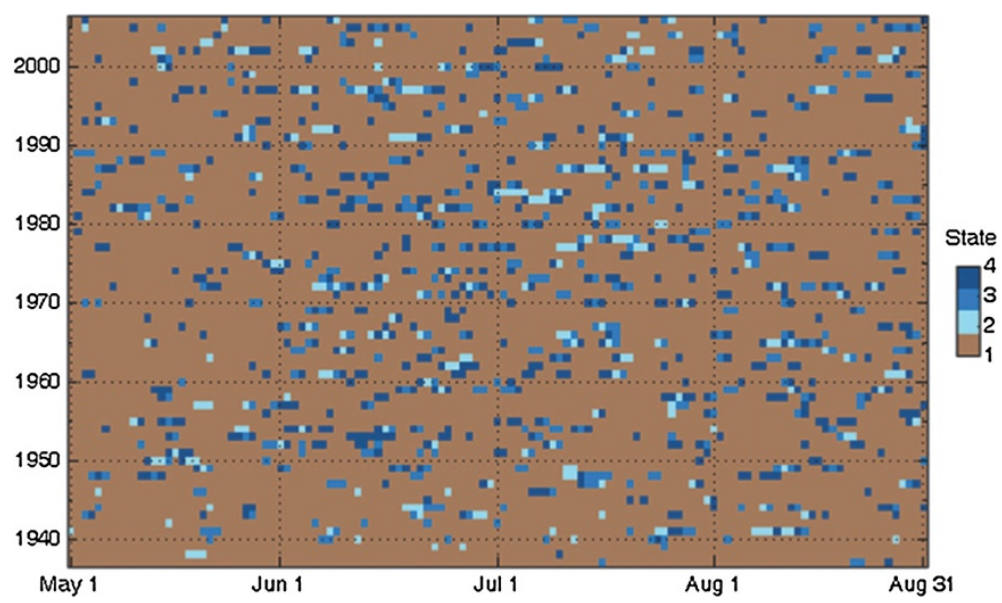

Figure 4 The most probable HMM state sequence for Chile. Rainfall states are indicated from driest (state 1) to wettest (state 4) on the color bar. Reproduced from (Verbist et al. 2010).

is affected by the Madden-Julian tropical intraseasonal oscillation (Barrett et al. 2011).

The NHMM can be used to generate large ensemble of daily rainfall sequences conditioned on the CFSv1 hindcasts enabling more refined drought indicators to be calculated. Figure 6 shows the skill of the CFSv1 forecasts downscaled in this way, in terms of the Ranked Probability Skill Score ${ }^{2}$ (RPSS) for (a) the frequency of heavy rainfall events $(>15 \mathrm{~mm}$ ), and the accumulated precipitation deficit (APD) which is the accumulation of daily precipitation deficit from May to August (Byun and Wilhite 1999); the median RPSS averaged across the stations is 0.25 and 0.12 respectively. Heavy rainfall event frequency is not generally found to be a very seasonally predictable quantity, so this is an encouraging result, and can be attributed to the strong association between the HMM heavy rainfall state 4 and ENSO (Verbist et al. 2010).

\section{Chile streamflow forecasts and water rights}

As mentioned above, water rights are set in October for the water year starting in October with a first statement issued in early May, and a final one in September. Numerous predictors from the suite of season-ahead hydroclimatic variables were evaluated for the Septemberissued forecast, but observed precipitation in the prior May-August season was found to give the best prediction of October-January streamflow. Twenty-four precipitation stations throughout the basin, from the

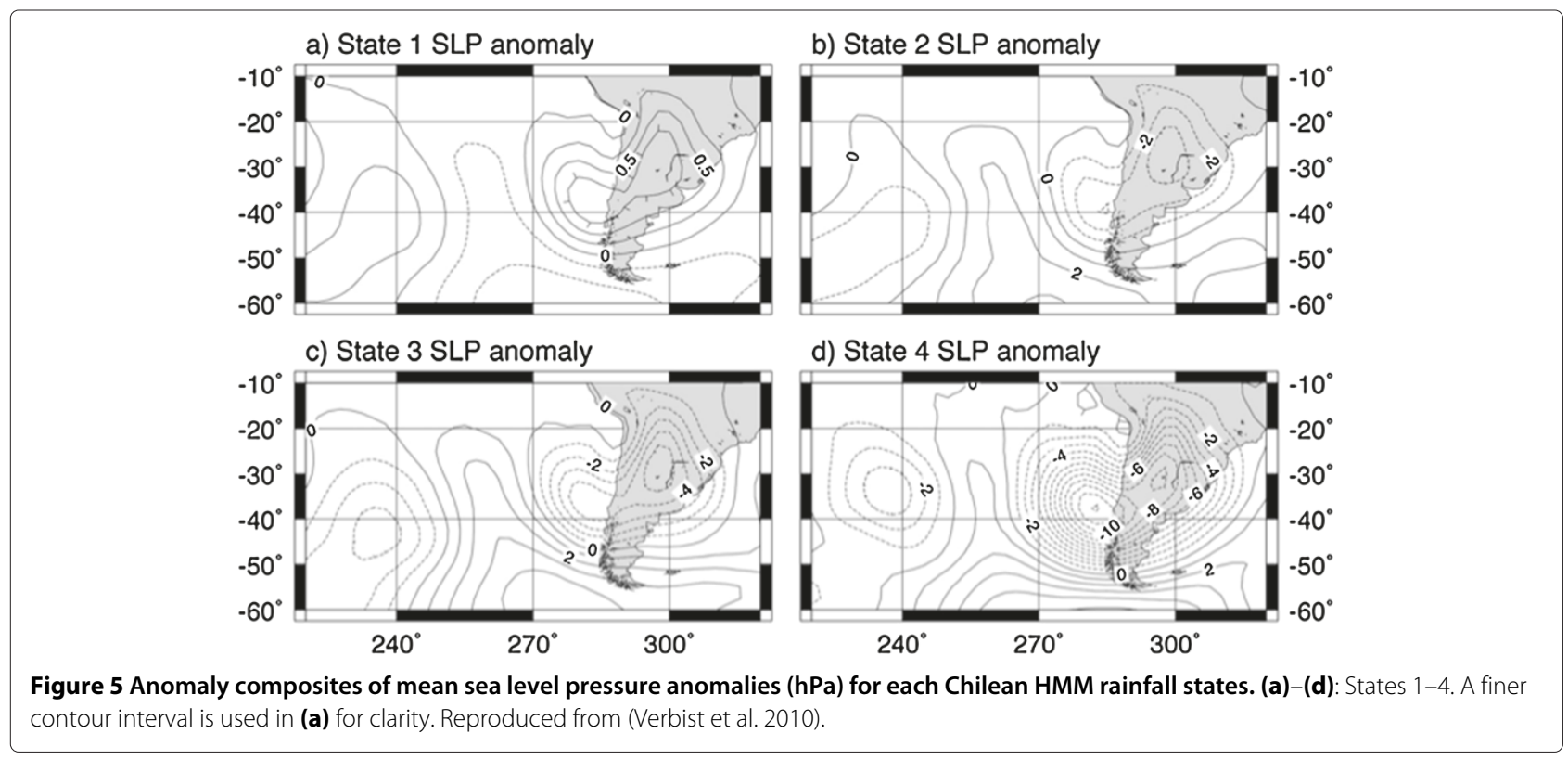



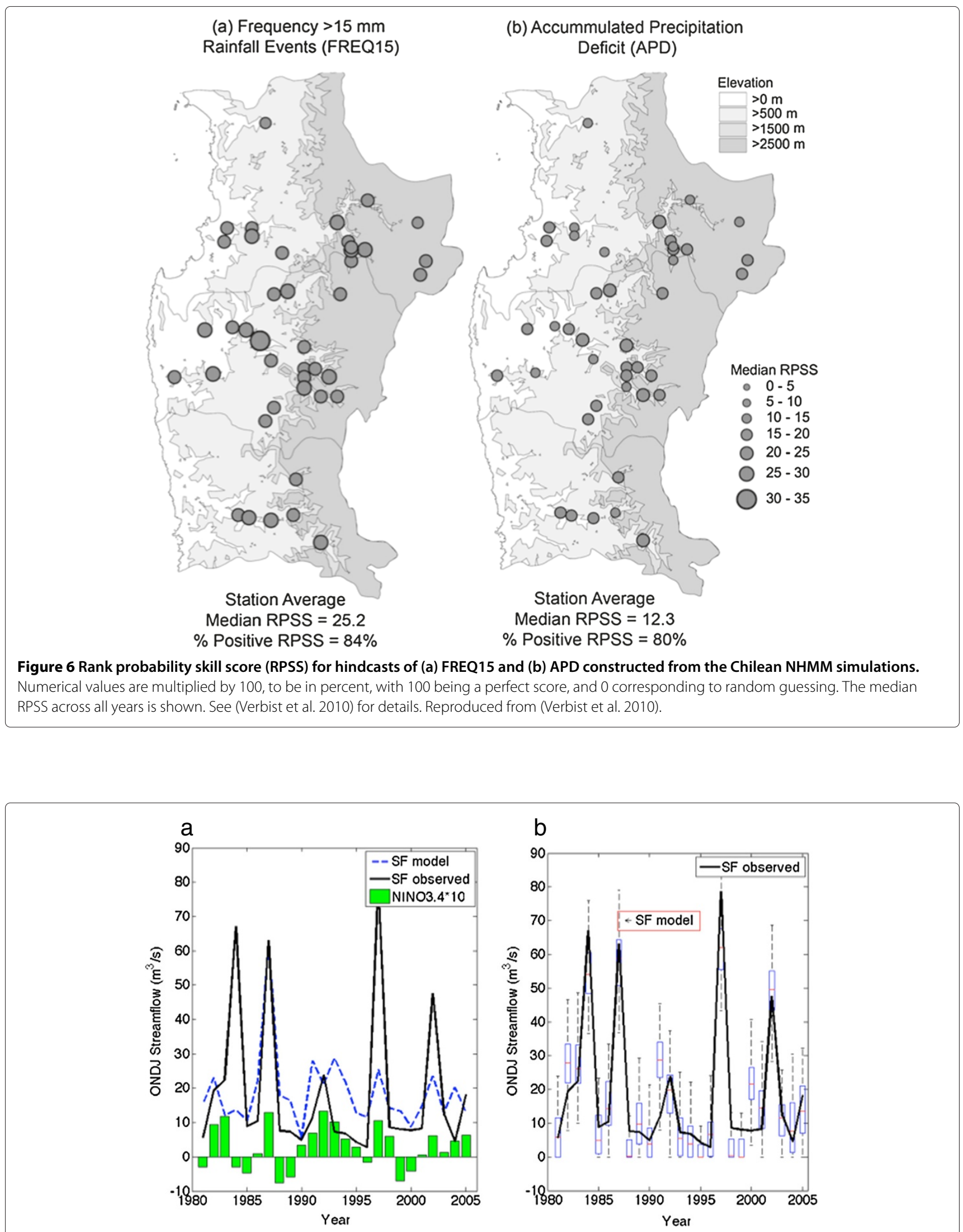

Figure 7 Hindcasts of Elqui River (Chile) October-January streamflow issued in (a) May and (b) September. Observed streamflow and Niño 3.4 values (units: tenths ${ }^{\circ} \mathrm{C}$ ) are also shown. 
Table 1 Chile water rights forecasts

\begin{tabular}{llcccc}
\hline \multicolumn{5}{c}{ Forecast streamflow } & \\
\hline & None & Moderate & Serious & Severe \\
\hline \multirow{2}{*}{ Observed } & Moderate & 5 & 1 & & \\
\hline Streamflow & Serious & 8 & 4 & \\
\hline & Severe & & 4 & 10 & 4 \\
\hline
\end{tabular}

Contingency table for September-issued water rights value forecast reduction from $1 \mathrm{~L} / \mathrm{s}$.

coast to the high elevations were included in the principal components regression model using CPT, following (Verbist et al. 2010). Snowpack data, which is very highly correlated with basin precipitation, also led to good skill, however the number of sites and length of record is still quite limited. Additionally, the national water authority is striving to convert many precipitation stations to real-time with online accessibility, which could eventually promote a fully automated forecast system.

The decision to use May-August precipitation observations for the September-issued forecast prompted the use of the CFSv1 forecast model to evaluate May-August precipitation forecasts for the May-issued forecast at all stations to subsequently predict streamflow. This was motivated by Verbist et al.s (2010) work and by a desire to use a single, uncomplicated, transparent framework relating wintertime precipitation with summertime streamflow.

Figure 7 illustrates predicted average October-January streamflow over 1981-2005, using (a) the CFSv1-based model ensemble median for the May-issued forecast, and (b) the full statistical model ensemble for the Septemberissued forecast.

The observed streamflow and Niño 3.4 index are also plotted. Not surprisingly, the September-issued forecast produces superior skill (ACC $=0.88$; RPSS $=0.5$ ), however the May-issued forecast is still notable $(\mathrm{ACC}=$ 0.49 ; RPSS $=-0.24)$, although the reasons for the negative RPSS score require further investigation. The ability of these models to predict categorically dry years is especially noteworthy. For the ten driest observed years, the September-issued forecast correctly predicts eight of those ten years. The September-issued forecast utilizing precipitation season-ahead observations is also markedly superior to the local authority's previous Septemberissued approach using the multivariate ENSO index and historical analogs (not shown).

Ensuing water rights value forecasts are produced categorically based on the September-issued forecast and reservoir volume, indicating potential reduction from the full value of $1 \mathrm{~L} / \mathrm{s}$. Categories include none, moderate $(0.5-1 \mathrm{~L} / \mathrm{s})$, serious $(0.25-0.5 \mathrm{~L} / \mathrm{s})$, and severe $(<0.25$ $\mathrm{L} / \mathrm{s})$. The forecasts perform quite well, and for missed categories, typically underestimate the rights value, favoring a conservative approach (Table 1). This is not as evident for the severe category, however, where approximately half of the occurrences were classified as serious, and one as moderate.

\section{Ceará streamflow forecasts}

Figure 8 shows K-NN hindcasts of July-June annual average Oros streamflow over the 1990-2000 period, based on antecedent April-June SSTs, using a model trained on the 1949-1990 period as described in the Methods Section.

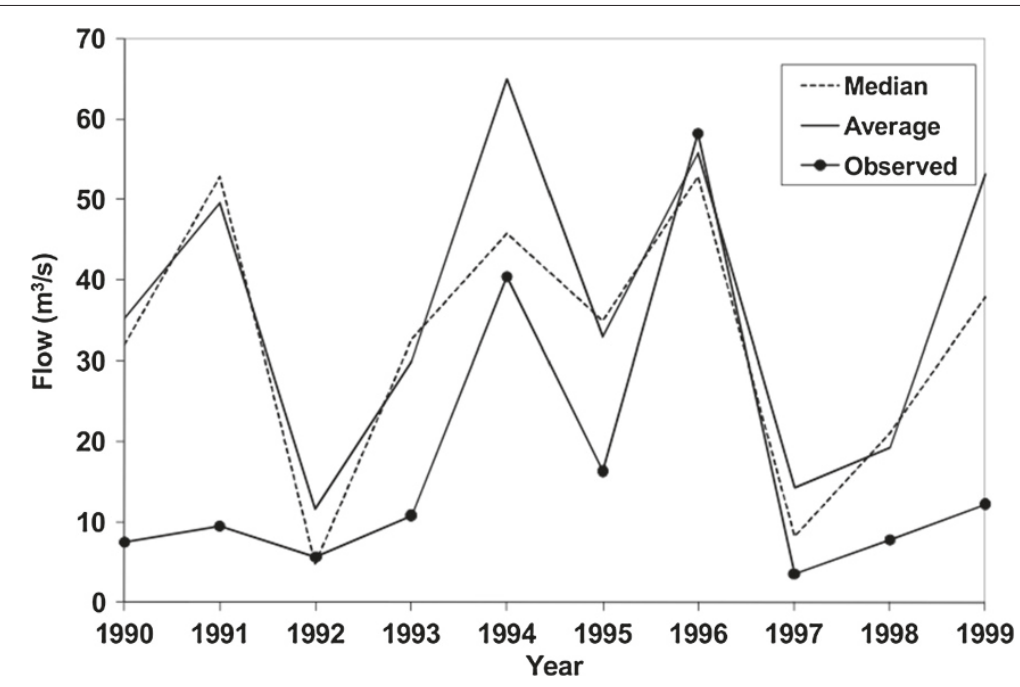

Figure 8 Hindcasts of Oros streamflow (NE Brazil) at 12-month lead made with the K-NN resampling method, trained on the 1949-1989 period. The median and average of the 1000-member hindcast ensembles are shown, along with the observations. Reproduced from (Sankarasubramanian et al. 2009a). 
The correlation between the observed annual flows and the ensemble-averaged hindcasts is 0.7 ; thus, the annual Oros flows can be predicted quite well up to a year in advance using antecedent SSTs, at least retrospectively over this 10 -year period.

\section{Streamflow forecasts for water allocation}

The monthly streamflow hindcasts in Figure 8 were next applied along with each year's initial available storage and user demands to calculate the optimal reservoir releases for each use, using the allocation model described in the Methods Section. Figure 9a shows that the forecastbased releases over the 10-year period are the same as those derived assuming zero inflow, except for an additional release for agriculture in 1993. To illustrate why, the simulated reliability of supply and initial storage available for allocation based on the hindcasts are plotted in
Figure 9b. During the period 1990-92, the observed flow was below-normal causing the reservoir to continuously deplete. By 1993, the agricultural demand exceeded the initial storage $\left(657 \mathrm{hm}^{3}\right.$, Figure $\left.9 \mathrm{~b}\right)$ could not meet the under the zero inflow assumption, reducing the which resulted in a reduced allocation of only $42 \mathrm{hm}^{3}$ for agriculture. However, the hindcasts predicted near-normal inflows in 1993 (Figure 8), leading to a larger hindcastbased allocation for agriculture (Figure 9a).

In 1994, with the simulated initial storage being at the lowest in 10 years, the simulated reliability of supply using the hindcasts was reduced to $90 \%$ for all uses, but recovered to $100 \%$ thereafter because of larger observed inflows (Figure 9b). Thus, the utility of climate forecasts is more pronounced during drought periods when the initial storage is less than the total demand.

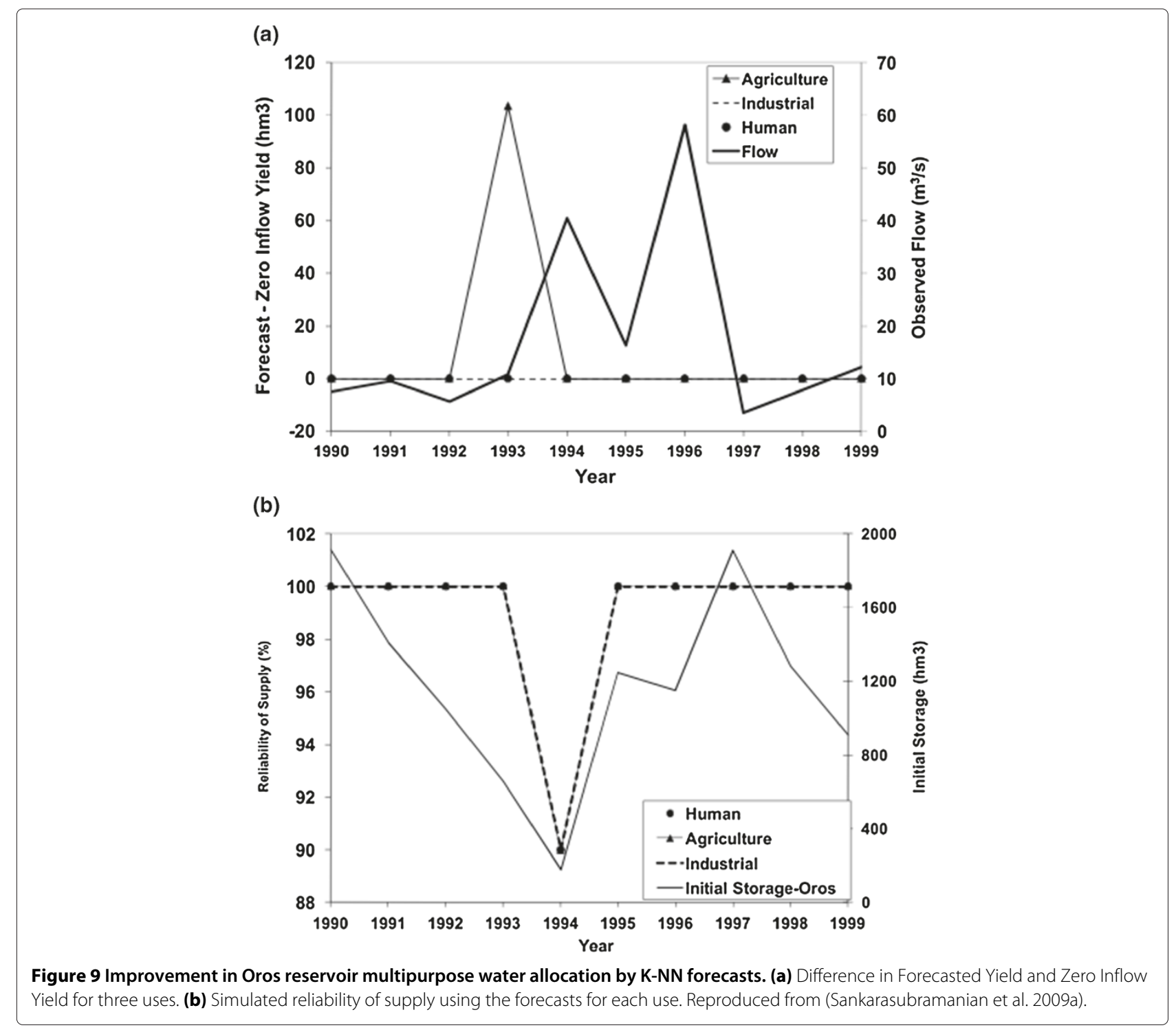


Since municipal use has the highest priority, its entire annual demand was allocated every year under both hindcast and zero inflows. This is also the case for industrial use, except in 1994, although even then there was no difference in releases since the allocations were zero using both schemes due to low initial storage conditions.

Since the ratio of storage to annual inflow volume for the Oros reservoir is 4.23 , we see limited improvements in water allocation using the seasonal streamflow forecasts in Figure 9. To generalize the findings on the utility of climate forecasts for different reservoir characteristics, Figure 10 shows the percentage improvement in water allocation for different reservoir system configurations using synthetic inflow forecasts having different skills (Sankarasubramanian et al. 2009a).

As forecast skill increases, the percentage improvement in water allocation relative to the climatological approach increases; however, the percentage improvement is much higher for systems having low storage to demand ratio. This is mainly because systems with large storage-to-demand ratio have the ability to supply the annual demand (including evaporation losses) from the initial storage alone; streamflow forecasts are much more potentially useful for smaller reservoirs relative to demand.

Sankarasubramanian et al., (2009) (Sankarasubramanian et al. 2009b) demonstrated a much higher potential utility of climate forecasts in improving reservoir operation for the Angat Reservoir in the Philippines, which is a withinyear storage system with a storage-to-demand ratio of only 0.83 .

Nonetheless, according to 2007 growth in the Ceará region is likely to lead to increased demand that will

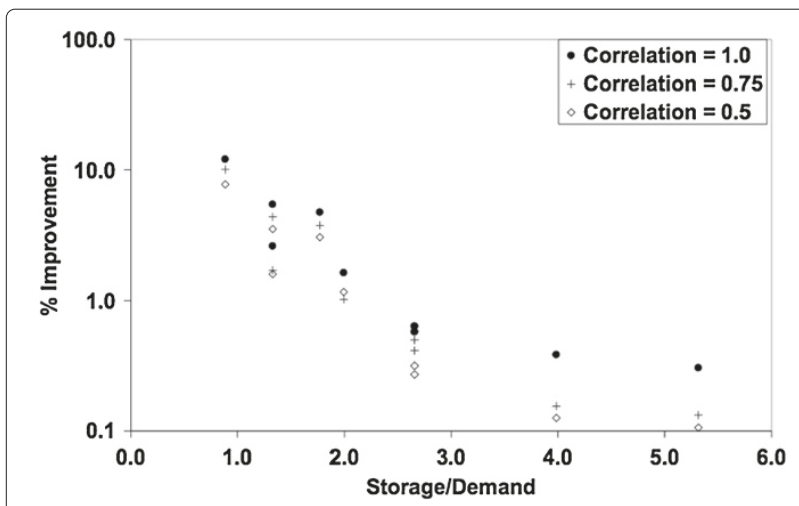

Figure 10 Utility of Streamflow forecasts in improving water allocation under different reservoir system configurations. Net annual yield corresponding to $90 \%$ reliability is obtained for each uses using the within year demand fractions given in Table one of (Sankarasubramanian et al. 2009a). Reproduced from (Sankarasubramanian et al. 2009a). constrain the system allocation more often, increasing the potential utility of climate forecasts.

In the Chilean Elqui River valley, the Puclaro reservoir has a high storage-to-demand ratio of 20 in normal to wet years, as demand is balanced against input from snow melt. In dry years, when precipitation amounts drop significantly, a large part of the reservoir is needed to fulfill demands, reducing the storage-to-demand ratio to 1.54 (Orphanopoulos et al. 2013). As these drought years have a return period of 6-7 years for this region (Nuñez et al. 2011), the potential for applying seasonal streamflow forecasting to optimize water allocation is expected to be significant.

This potential is likely to further increase, given the observed decreasing trend of precipitation in the region, as well as the further decline projected by the different climate change scenarios (Solomon et al. 2007). The current multi-year drought (2009-2013), for example, has reduced the storage of the Puclaro reservoir to a historical low level of only $5 \%$, eliminating its buffering capacity for upcoming years. Under such conditions, agriculture will be directly dependent on precipitation from the previous season, and could benefit greatly from anticipated seasonal outlooks for planning purposes.

\section{Conclusions}

This paper has reviewed IRI work in Chile and NE Brazil that assesses the potential for using seasonal climate forecasts to improve management of drought and water resources in semi-arid regions. In both locations, downscaled precipitation forecasts made with statistical models based on lagged SST predictors or GCM precipitation forecasts have quite high skill. For drylands management in Chile, these forecasts were expressed in terms of station and regional-scale drought indices based on daily rainfall sequences, which better matches the approach used by local drought agencies than does the three-month rainfall totals in global seasonal forecasts, in additional to being more spatially specific. Extension of the analysis southwards, as presented in this paper, indicates that the seasonal forecast skill remains high, which warrants application of the methodology in the whole central Chilean drylands.

Streamflow in central-northern Chile is largely snowfed, and in some new work reported here, this springsummer melt flow is shown to be highly predictable based on observed estimates of precipitation in the previous winter, but also to be moderately predictable up to 6 months in advance using climate forecasts. These streamflow forecasts were shown to be quite effective in retrospectively predicting categories of reduction in water rights during dry years. In 2011, the September forecast was incorporated into the decision making process of the Elqui Water Authority. Three scenarios were presented 
to the stakeholders, showing distinct options for water allocation for the following summer season, based on the seasonal forecast, the available reservoir storage and the requested water allocation. This first experience confirmed the potential of seasonal forecasting as an integral part of the water allocation decision support system. Turning the seasonal forecast model into an operational product remains a challenge, however, as this requires further integration of data sets that are currently collected manually. Different alternatives of remote sensing proxies for precipitation in the region are also currently being evaluated.

Reservoir managers in Ceará must manage water releases to supply agreed-upon allocations for municipal, industrial and agricultural users, with a given level of reliability. Currently, a conservative policy is used that assumes zero inflow into the reservoir in the upcoming year-essentially assuming a drought will occur every year, and allocating water from the beginning-of-year storage. Climate forecasts tailored to streamflow are shown to have the most potential to optimize this practice during multi-year low-flow periods where the beginning-of-year storage is low. However, the Oros reservoir is a large multi-yearstorage reservoir, and the highest potential for utilizing climate forecasts is shown to be for smaller reservoirs, relative to demand. As human demands for water rise over time, the number of such reservoirs is certain to rise.

Since 2011, the water supply agency in Ceará, COGERH, has implemented the use of the climate forecasts and reservoir optimization scenarios as part of its regular water allocation process. An initial implementation took place through the quarterly stakeholder meetings at the Curu reservoir. In 2012, the program was extended to 13 reservoirs in the system. Forecasts are updated and provided by the regional natural resource agency FUNCEME, and training to COGERH on forecast development, interpretation and use with the optimization models was provided by the Federal University of Ceará in Fortaleza. At this point the process has been institutionalized within COGERH. Current constraints on the use of these forecasts are likely to be reduced by shifts in water demand, water allocation in the agricultural Jaguaribe Valley, participatory processes for water allocation between this valley and the capital city of Fortaleza, and risk perception. The qualitative analysis by (Broad et al. 2007), based upon extensive fieldwork with farmers, agencies, politicians and other key actors in the water sector, stresses that forecast value changes as a society shifts.

\section{Endnotes}

${ }^{1}$ If the over-year volume is very low, water rights values will likely be reduced even if the inflow is normal or above to promote refilling the reservoir. This is at the discretion of the operators, but typically these reductions begin when the reservoir is at half capacity or less.

${ }^{2}$ It can be shown that, in the idealized case of well-calibrated normally distributed forecasts, $R P S S \sim 1-\sqrt{1-r^{2}}$ where $r$ is the anomaly correlation coefficient. An ACC of 0.4 equates to an RPSS of about 0.08 .

\section{Competing interests}

The authors declare that they have no competing interests.

\section{Authors' contributions}

AWR led and coordinated the manuscript writing and integrating the contributions from the coauthors; he also wrote the Chile rainfall downscaling sections. WB contributed to the Chile work. PB wrote the Chile water rights modeling and forecasting sections. UL and FASF contributed to the NE Brazil work. AS wrote the NE Brazil reservoir management sections. KV supported the development of the drought forecast model for the Chilean drylands and contributed to the writing. All authors read and approved the final manuscript.

\section{Acknowledgements}

This work was funded by NOAA under a cooperative agreement with the IRI.

Responsible editor: Michael Piasecki

\section{Author details}

${ }^{1}$ International Research Institute for Climate and Society, The Earth Institute, Columbia University, Palisades, New York, USA. ${ }^{2}$ Department of Civil \& Environmental Engineering, University of Wisconsin-Madison, Wisconsin, USA ${ }^{3}$ Dept. of Earth \& Environmental Engineering, Columbia University, New York, USA. ${ }^{4}$ Dept. of Civil, Construction \& Environmental Engineering, North Carolina State University, Raleigh, NC, USA. ${ }^{5}$ Dept. of Hydrology, Federal University of Ceará, Fortaleza, Brazil. ${ }^{6}$ UNESCO-IHP, Hydrological Systems and Global Change section, Santiago, Chile. ${ }^{7}$ International Centre for Eremology, Department of Soil Management, Ghent University, Ghent, Belgium.

Received: 1 October 2013 Accepted: 3 March 2014

Published: 17 June 2014

\section{References}

Aceituno P (1988) On the functioning of the Southern Oscillation in the South American sector. Part I: Surface climate. Mon Weather Rev 116: 505-524

Barnston AG, Li S, Mason SJ, DeWitt DG, Goddard L, Gong X (2009) verification of the first 11 years of IRI's seasonal climate forecasts. J Appl Meteorol Climatol 49(3): 493-520. [http://dx.doi.org/10.1175/2009JAMC2325.1]

Barrett BS, Carrasco JF, Testino AP (2011) Madden-Julian Oscillation (MJO) modulation of atmospheric circulation and Chilean winter precipitation. J Climate 25(5): 1678-1688

Broad K, Pfaff A, Taddei R, Sankarasubramanian A, Lall U, de Assis de Souza Filho $F$ (2007) Climate, stream flow prediction and water management in northeast Brazil: societal trends and forecast value. Climatic Change 84(2): 217-239. [http://dx.doi.org/10.1007/s10584-007-9257-0]

Byun HR, Wilhite DA (1999) Objective quantification of drought severity and duration. J Climate 12: 2747-2756

Carrasco JF, Osorio R, Casassa G (2008) Secular trend of the equilibrium-line altitude on the western side of the southern Andes, derived from radiosonde and surface observations. J Glaciology 54(186): 538-550

Challinor AJ, Wheeler TR, Craufurd PQ, Slingo JM, Grimes DIF (2004) Design and optimisation of a large-area process-based model for annual crops. Agric Forest Meteorol 124(1-2): 99-120. [http://www.sciencedirect.com/ science/article/pii/S0168192304000085]

Charles SP, Bates BC, Hughes JP (1999) A spatiotemporal model for downscaling precipitation occurrence and amounts. J Geophys Res-Atmospheres 104(D24): 31657-31669

Donoso G (2006) Water markets: case study of Chile's 1981 water code. Cienc Investig Agrar 33: 131-146

Falvey M, Garreaud R (2007) Wintertime precipitation episodes in central Chile: associated meteorological conditions and orographic influences. J Hydrometeor 8: 171-193 
Gangopadhyay S, Clark M, Rajagopalan B (2005) Statistical downscaling using K-nearest neighbors. Water Resour Res 41: W02024, doi:10.1029/2004WR003444

Garreaud R, Vuille M, Compagnucci R, Marengo J (2009) Present-day South American climate. Palaeogeogr Palaeocl 281: 180-195

Guttman N (1998) Comparing the palmer drought index and the standardized precipitation index. J Amer Water Resour Assoc 34: 113-121

Hansen JW, Challinor A, Ines A, Wheeler T, Moron V (2006) Translating climate forecasts into agricultural terms: advances and challenges. Climate Res 33: $27-41$

Hastenrath S, Heller L (1977) Dynamics of climatic hazards in Northeast Brazil. Quart J R Meteor Soc 103(435): 77-92

Hughes JP, Guttorp P (1994) A class of stochastic models for relating synoptic atmospheric patterns to regional hydrologic phenomena. Water Resour Res 30: 1535-1546

Kwon HH, de Assis de SouzaFilho F, Block P, Sun L, Lall U, Reis DS (2012) Uncertainty assessment of hydrologic and climate forecast models in Northeastern Brazil. Hydrological Process 26(25): 3875-3885. [http://dx.doi. org/10.1002/hyp.8433]

Lall U (1995) Yield model for screening surface-water and groundwater development. J Water Resour Plann Manage 121: 9-22

Lall U, Miller C (1988) An optimization model for multi-purpose, multi-reservoir screening, with explicit yield reliability consideration. Water Resour Res 24(7): 953-968

Montecinos A, Aceituno P (2003) Seasonality of the ENSO-related rainfall variability in central Chile and associated circulation anomalies. J Climate 16: $281-296$

Moron V, Robertson AW, Ward MN (2006) Seasonal predictability and spatial coherence of rainfall characteristics in the tropical setting of Senegal. Mon Weather Rev 134(11): 2148-2148

Moron V, Robertson AW, Ward MN, Camberlin P (2007) Spatial coherence of tropical rainfall at the regional scale. J Climate 20(21): 5244-5263

Moron V, Robertson AW, Ward MN, Ndiaye O (2008) Weather types and rainfall over Senegal. Part II: downscaling of GCM simulations. J Climate 21: $288-307$

Moura AD, Shukla J (1981) On the dynamics of droughts in Northeast Brazil - observations, theory and numerical experiments with a general-circulation model. J Atmos Sci 38(12): 2653-2657

Nobre P, Shukla J (1996) Variations of sea surface temperature, wind stress, and rainfall over the tropical Atlantic and South America. J Climate 9(10): 2464-2479

Nuñez JH, Verbist K, Wallis J, Schaeffer M, Morales L, Cornelis W (2011) Regional frequency analysis for mapping drought events in north-central Chile. J Hydrol 405: 352-366

Orphanopoulos D, Verbist K, Chavez A, Soto G (2013) Water use efficiency in an arid watershed: a case study. Sci Cold Arid Regions 5: 16-26

Quintana JM, Aceituno P (2012) Changes in the rainfall regime along the extratropical west coast of South America (Chile). 30-43S. Atmosfera 25:1-22

Rajagopalan B, Lall U (1999) A k-nearest-neighbor simulator for daily precipitation and other weather variables. Water Resour Res 35: 3089-3102

Robertson AW, Mechoso CR (2003) Circulation regimes and low-frequency oscillations in the South Pacific sector. Mon Weather Rev 131(8): 1566-1576

Robertson AW, Kirshner S, Smyth P (2004) Downscaling of daily rainfall occurrence over Northeast Brazil using a hidden Markov model. J Climate 17: 4407-4424

Robertson AW, Kirshner S, Smyth P, Charles SP, Bates BC (2006) Subseasonal-to-interdecadal variability of the Australian monsoon over North Queensland. Quart J R Meteor Soc 132: 519-542

Robertson AW, Moron V, Swarinoto Y (2009) Seasonal predictability of daily rainfall statistics over Indramayu district, Indonesia. Int J Climatol 29: 1449-1462

Robertson AW, Qian JH, Tippett MK, Moron V (2011) Downscaling of seasonal rainfall over the Philippines: Dynamical vs. statistical approaches. Mon Wea Rev 140: 1204-1218

Saha S, Nadiga S, Thiaw C, Wang J, Wang W, Zhang Q, Van den Dool HM, Pan HL, Moorthi S, Behringer D, Stokes D, Peña M, Lord S, White G, Ebisuzaki W, Peng P, Xie P (2006) The NCEP climate forecast system. J Climate 19(15): 3483-3517
Sankarasubramanian A, Lall U, de Souza Filho F, Sharma A (2009a) Improved water allocation utilizing probabilistic climate forecasts: short term water contracts in a risk management framework. Water Resour Res 45(W11409)

Sankarasubramanian A, Lall U, Devineni N, Espunevea S (2009b) Utility of operational streamflow forecasts in improving within-season reservoir operation. J Appl Meteor Climatol 48(7): 1464-1482

Solomon S, Qin D, Manning M, Chen Z, Marquis M, Averyt K, Tignor M, Miller H (eds) (2007) Contribution of Working Group I to the Fourth Assessment Report of the Intergovernmental Panel on Climate Change. Cambridge University Press, Cambridge, United Kingdom and New York, NY, USA

Souza Filho FA, Lall U, Water Resour Res, 39, 11 (2003) Seasonal to interannual ensemble streamflow forecasts for Ceara, Brazil: Applications of a multivariate, semiparametric algorithm: 1307. [http://dx.doi.org/10.1029/ 2002WR001373]

Tippett MK, Barlow M, Lyon B (2003) Statistical correction of Central Southwest Asia winter precipitation simulations. Internat J Climatol 23: 1421-1433

Verbist K, Robertson AW, Cornelis WM, Gabriels D (2010) Seasonal predictability of daily rainfall characteristics in central-northern Chile for dry-land management. J Appl Meteorol Climatol 49: 1938-1955

Wolter K, Timlin M (1998) Measuring the strength of ENSO - how does 1997/98 rank? Weather 53: 315-324

Wood A, Maurer E, Kumar A, Lettenmaier D (2002) Long-range experimental hydrologic forecasting for the eastern United States. J Geophys Res 107(D20): 4429, doi:10.1029/2001JD000659

Young G, Zavala H, Wandel J, Smit B, Salas S, Jimenez E, Fiebig M, Espinoza R, Diaz H, Cepeda J (2010) Vulnerability and adaptation in a dryland community of the Elqui Valley. Climatic Change 98: 245-276

\section{doi:10.1186/2194-6434-1-12}

Cite this article as: Robertson et al: Climate risk management for water in semi-arid regions. Earth Perspectives 2014 1:12

\section{Submit your manuscript to a SpringerOpen ${ }^{\circ}$ journal and benefit from:}

- Convenient online submission

- Rigorous peer review

- Immediate publication on acceptance

- Open access: articles freely available online

- High visibility within the field

- Retaining the copyright to your article

Submit your next manuscript at $\boldsymbol{\triangleright}$ springeropen.com 